\title{
Factors associated with polypharmacy in geriatrics
}

\author{
Geeta Rathod*, Nalini G. K., Jayashree V. Nagaral, Sahana G. N., Deepak P., \\ M. Prema, Nuthan Kumar U. S.
}

Department of Pharmacology, Hassan Institute of Medical Sciences, Hassan, Karnataka, India

Received: 06 May 2017

Revised: 22 May 2017

Accepted: 31 May 2017

*Correspondence to:

Dr. Geeta Rathod,

Email: geet6rathod@gmail.com

Copyright: (C) the author(s), publisher and licensee Medip Academy. This is an openaccess article distributed under the terms of the Creative Commons Attribution NonCommercial License, which permits unrestricted noncommercial use, distribution, and reproduction in any medium, provided the original work is properly cited.

\begin{abstract}
Background: In population with advancing age, the prevalence of medical comorbid conditions is high and they are prone for complications. Hence the apprehension of using multiple drugs is more. Using more than 5 drugs per day is referred to as Polyphrmacy. Sometimes treatment causes more harm than the disease proper. So, optimizing drug therapy in these aging population is a challenging task for physician. Polypharmacy can also lead to increase in drug interactions, adverse drug reactions and medication errors. Hence the present study was taken up to study drug utilization pattern and factors leading to polypharmacy in geriatrics. The objectives of the study were to study the number and type of drug use and to know the different factors leading to polypharmacy.
\end{abstract}

Methods: Cross sectional study was carried out among 60 geriatric persons $\geq 60$ years of age present in old age home in Hassan. The study was done after taking the consent. All the prescriptions and medications being used along with history were collected and documented. The total number of drugs being used and names of all drugs were noted down and analysed. Results were analysed using descriptive statistics.

Results: Among 60 geriatrics 38\% males and $62 \%$ females age ranges from 60 87 years. Average number of drugs used per day per person is 5.03 (Males 6.2 and Females 3.8) in 58.03\% of individuals. Most common group of drug used is Gastro intestinal system (78.3\%) and most common drug being used is Tab. Ranitidine 140mg (50\%). Next group is NSAIDs $(68.33 \%)$ and most common drug being used is Tab. Diclofenac (46.7\%). Antihypertensive drugs were prescribed in $53.3 \%$ of geriatrics, most commonly prescribed drug is Tab. Amlodipine $(5 \mathrm{mg})$. Self medication was found in $100 \%$. Most common group of drugs used as self medication are GIT drugs, supplements and NSAIDs. In supplements (used in 63.3\%), Cap. B Complex is widely used (50\%).

Conclusions: Polypharmacy was found in $58.3 \%$ of individuals and highest in age group between 71-75 years and self medication was found to be the most important factor leading to polypharmacy. To counteract the problems associated with Polypharmacy, interventional studies are needed to improve the quality of life of geriatrics patients.

Keywords: Drug use, Geriatrics, Polypharmacy, Self medication

\section{INTRODUCTION}

World Health Organization has evaluated that in every nine people there is one elderly individual, i.e. of age $>60$ years.

This value is to be expected to increase to one in five by 2050 accounting for about half of the total growth of the world population. ${ }^{1}$
Coming to Indian scenario, India is in a phase of demographic transition. As per the 1991 census, the population of the elderly in India was 57 million as compared with 20 million in 1951. There has been a sharp increase in the number of elderly persons between 1991 and 2001 and it has been projected that by the year 2050 , the number of elderly people would rise to about 324 million. Thus India has acquired the label of "an 
ageing nation" with $7.7 \%$ of its population being more than 60 years old. ${ }^{2}$

This demographic transition in the elderly population constitutes a significant challenge for health authorities worldwide as with advancing age multiple chronic diseases such as hypertension, diabetes mellitus, arthritis, chronic heart disease, renal diseases, etc. are associated. ${ }^{1}$

Thus often Ageing comes with the chronic illnesses, comorbidity, disability and social isolation. These higher rates of chronic illness increase the likelihood of taking multiple medications by older people. It is very rare for elderly patients to have accompanied with only one disease. So Polypharmacy is becoming a common problem among elderly individuals. ${ }^{3}$

It is estimated that multiple comorbid conditions ranging from 55 to $98 \%$ among the elderly. National Health and Nutrition Examination Survey (NHANES III) reveals that nearly $74 \%$ of elderly population in India use prescribed medications. Half of them aged 65-74years use 2 or more prescribed drugs and $12 \%$ of them use 5 or more prescribed drugs. ${ }^{3}$

There is no as such standard definition of polypharmacy. As polypharmacy has no standard definition, according to Kaufman the use of more than 5 drugs means Polypharmacy. Kaufman grouped prescribed medications into four groups $<4,5-9,10-14$ and $>15$ medications per day. ${ }^{4}$

Various studies globally have shown that on an average 2-9 medications per day are taken by the elderly people. The prevalence of inappropriate medication used by the elderly people was found to be from $11.5-62.5 \%$. $^{2,5}$

Prevalence of polypharmacy in India is $4.2 \%$ which is large proportion of elderly in India. ${ }^{3}$ The burden of taking multiple medications has been associated with greater healthcare costs and an increased risk of adverse drug events (ADEs), drug interactions, medication non adherence, reduced functional capacity and multiple geriatric syndromes. ${ }^{6}$

It has been claimed that patients taking two drugs face a $13 \%$ risk of adverse drug interactions, rising to $38 \%$ when taking four drugs and to $82 \%$ if seven or more drugs are given simultaneously. With polypharmacy, duplicative prescribing within the same drug class is prevalent and unrecognized drug adverse-effects are often treated with more drugs thus leading to prescribing cascades. $^{7}$

Use of inappropriate medication among elderly patients is a major public health concern. It is estimated to be the fifth major cause of death. Polypharmacy can lead to affect the quality of life of the elderly. There are very few studies in the predictors of polypharmacy among elderly in India. So the present study has been taken to study factors associated with polypharmacy in geriatrics.

\section{METHODS}

Cross sectional observational study was conducted in an old age home "Kamadhenu Vruddhashrama" in Hassan district, Karnataka. IEC clearance was taken before starting the study. Verbal consent was taken from all the study participants. Individuals who were not willing to participate in the study were excluded from the study. 60 geriatrics were included in the study.

Demographic details of all the geriatrics were collected and noted down in a preformed proforma. Detailed history was taken about diagnosis, comorbid illnesses and treatment. All the medication documents and medications being used were collected and analysed. Details about medications like- drug, dose, dosage, whether prescribed or self medicated, side effects, duration of intake, total number of drugs being used.

\section{Statistical analysis}

Results analysed using descriptive statistics and percentage analysis

\section{RESULTS}

60 geriatrics were included in the study. Table 1 shows demographic details of the study participants. Out of 60 , 27 were males and 33 were females. $30 \%$ of them were in age group between $66-70$. $20 \%$ of them belonged to 60 65 and $71-75$ age group. $10 \%$ were >80years of age (Table 1).

Table 1: Demographic Details.

\begin{tabular}{|llll|}
\hline Age group & Males & Females & Total no. \\
\hline $60-65$ & 6 & 6 & $12(20 \%)$ \\
\hline $66-70$ & 7 & 12 & $19(30 \%)$ \\
\hline $71-75$ & 6 & 6 & $12(20 \%)$ \\
\hline $76-80$ & 3 & 4 & $7(13.33 \%)$ \\
\hline$>80$ & 5 & 5 & $10(16.7 \%)$ \\
\hline Total number & 27 & 33 & \\
\hline
\end{tabular}

Table 2: Average number of medications used/day.

\begin{tabular}{|ll|}
\hline $\begin{array}{l}\text { Average number of medications/ } \\
\text { day }\end{array}$ & Percentage (N) \\
\hline$\leq 4$ & $41.66(25)$ \\
\hline $5-9$ & $56.66(34)$ \\
\hline $10-14$ & $1.66(01)$ \\
\hline$>14$ & 00 \\
\hline
\end{tabular}

According to Kuffman's grading, 60 geriatrics were divided into four groups- $\leq 4,5-9,10-14$ and $>14$ medications per day. Polypharmacy was found (>5 medications/ day) in $58 \%$ of geriatrics. $56.66 \%$ of them 
found to be using 5-9 medications/ day. $41.66 \%$ of them using $\leq 4$ medications/day (Table 2).

Polypharmacy was found in age groups of 60-65 and 71$75,5.1$ and 5.3medications/day respectively. In age group of 66-70 and 76-80 years, average medication/ day was 4.6. In $>80$ years of age group 4.8 (Table 3 ).

Table 3: Age wise usage of average medications/ day.

\begin{tabular}{|lll|}
\hline $\begin{array}{l}\text { Age group } \\
\text { (years) }\end{array}$ & $\begin{array}{l}\text { Percentage } \\
(\mathbf{N})\end{array}$ & $\begin{array}{l}\text { Average number of } \\
\text { drugs consumption/ day }\end{array}$ \\
\hline $60-65$ & $20(12)$ & 5.1 \\
\hline $66-70$ & $30(19)$ & 4.6 \\
\hline $71-75$ & $20(12)$ & 5.3 \\
\hline $76-80$ & $13.3(7)$ & 4.6 \\
\hline$>80$ & $16.7(10)$ & 4.8 \\
\hline
\end{tabular}

Polypharmacy was found in males with 5.04 medications/day. In females average medications/ day was 3.94 (Table 4).

Table 4: Sex wise distribution of average mediactions/day.

\begin{tabular}{|lll|}
\hline Sex & Percentage $(\mathbf{N})$ & $\begin{array}{l}\text { Average number of } \\
\text { drugs consumption }\end{array}$ \\
\hline Male & $38.33(23)$ & 5.04 \\
\hline Female & $61.66(37)$ & 3.94 \\
\hline
\end{tabular}

Among associated Clinical Conditions- Hypertension was found in $53.33 \%$ of study participants. Diabetes mellitus was found in $35 \%$, COPD $18.33 \%$ and osteoarthritis in $20 \%$. Gastritis was found in only $10 \%$ of individuals (Table 5).

Table 5: Associated clinical conditions.

\begin{tabular}{|ll|}
\hline Clinical condition & Percentage (N) \\
\hline Hypertension & $53.33(32)$ \\
\hline Diabetes mellitus & $35(21)$ \\
\hline COPD & $18.33(11)$ \\
\hline Osteoarthritis & $20(12)$ \\
\hline Gastritis & $10(6)$ \\
\hline $\begin{array}{l}\text { Others (dyslipidemia, CVA, PVD, } \\
\text { epilepsy) }\end{array}$ & $16.66(10)$ \\
\hline
\end{tabular}

GIT drugs were used in $78.33 \%$ of individuals, NSAIDs $68.33 \%$, Vitamins $63.33 \%$ and CVS drugs in $53.33 \%$ of individuals. Respiratory system and CNS dugs usage was found only in 10 and $11.6 \%$ of individuals.

Usage of cardiovascular drugs was seen in $53.33 \%$ of study participants. Among these calcium channel blockers like Amlodipine usage was found in $43.33 \%$. ARBs like Losartan and Telmisartan and Beta blockers like Atenolol and Metaprolol usage was found in $15 \%$ of individuals. Antiplatelets like Aspirin and Clopidogrel and Statins like Atorvastatin usage was found in $8.33 \%$ and $5 \%$ respectively.

Gastro intestinal system drugs were used in $78.33 \%$ of study participants. Among them $\mathrm{H} 2$ blockers like Ranitidine were found to be used in $51.66 \%$ of individuals. Proton pump inhibitors like Omeprazole and Pantoprazole and Drugs for constipation like Bisacodyl were used in $33.33 \%$ and $16.66 \%$ respectively. Antimotility like Loperamide drugs were used in $5 \%$ of individuals.

Endocrine system drugs were used in $30 \%$ individuals. Oral hypoglycemic agents like Metformin, sulfonylureas were the commonly used drugs almost $50 \%$. Insulin usage was found only in $1.66 \%$ of individuals.

NSAIDs like Paracetamol, Diclofenac, Nimesulide were used in $68.33 \%$ of individuals.

Respiratory system drugs like Theophylline, salbutamol was used in $28.33 \%$ of individuals and other drugs like B. Complex, Calcium (Multi vitamins) usage was $65 \%$ (Table 6).

Table 6: System wise commonly used drugs.

\begin{tabular}{|c|c|c|}
\hline System & Drugs & $\%(\mathrm{n})$ \\
\hline \multirow{5}{*}{$\begin{array}{l}\text { Cardiovascular } \\
\text { system }\end{array}$} & $\begin{array}{l}\text { Calcium channel } \\
\text { blockers (Amlodipine) }\end{array}$ & $\begin{array}{l}43.3 \\
(26)\end{array}$ \\
\hline & $\begin{array}{l}\text { ARBs (Losartan/ } \\
\text { Telmisartan) }\end{array}$ & $15(9)$ \\
\hline & $\begin{array}{l}\text { Beta blockers (Atenolol, } \\
\text { Metaprolol) }\end{array}$ & $15(9)$ \\
\hline & $\begin{array}{l}\text { Antiplatelet (Aspirin, } \\
\text { Clopidogrel) }\end{array}$ & $8.33(5)$ \\
\hline & Statins (Atorvastatin) & $5(3)$ \\
\hline \multirow{4}{*}{$\begin{array}{l}\text { Gastro } \\
\text { intestinal } \\
\text { system }\end{array}$} & H2 blockers (Ranitidine) & $\begin{array}{l}51.66 \\
(31)\end{array}$ \\
\hline & $\begin{array}{l}\text { Proton pump inhibitors } \\
\text { (Omeprazole, } \\
\text { pantoprazole) }\end{array}$ & $\begin{array}{l}33.33 \\
(20)\end{array}$ \\
\hline & $\begin{array}{l}\text { Drugs for constipation } \\
\text { (Bisacodyl) }\end{array}$ & $\begin{array}{l}16.66 \\
(10)\end{array}$ \\
\hline & $\begin{array}{l}\text { Antimotility drugs } \\
\text { (Loperamide) }\end{array}$ & $5(3)$ \\
\hline \multirow[t]{2}{*}{$\begin{array}{l}\text { Endocrine } \\
\text { system }\end{array}$} & $\begin{array}{l}\text { Oral hypoglycemic } \\
\text { agents (Metformin, } \\
\text { sulfonylureas) }\end{array}$ & $50(30)$ \\
\hline & Insulin & $1.66(1)$ \\
\hline NSAIDs & $\begin{array}{l}\text { Paracetamol, Diclofenac, } \\
\text { Nimesulide }\end{array}$ & $\begin{array}{l}68.33 \\
(41)\end{array}$ \\
\hline $\begin{array}{l}\text { Respiratory } \\
\text { system }\end{array}$ & Theophylline, salbutamol & $\begin{array}{l}28.33 \\
(17)\end{array}$ \\
\hline Others & $\begin{array}{l}\text { B. Complex, Calcium } \\
\text { (Multi vitamins) }\end{array}$ & $65(39)$ \\
\hline
\end{tabular}

To compare age wise prescribing frequency of group of drugs. Among 60-65 age group GIT and another drugs 
usage was more. In 66-70 years age group CVS, GIT and other drugs were used more. In >80years age group of individuals GIT drugs usage was more compared to other drugs. Average frequency of usage of group of drugsother group of drugs 8.33, GIT drugs 8.5, NSAIDs 6.5, CVS drugs 5.66 Endocrine 4 and RS drugs 2.16 (Table 7).

Table 7: Age wise prescribing frequency of group of drugs.

\begin{tabular}{|lllllll|}
\hline $\begin{array}{l}\text { Age } \\
\text { (years) }\end{array}$ & CVS & GIT & Endocrine & NSAIDs & RS & Others \\
\hline $60-65$ & 8 & 11 & 5 & 6 & 2 & 10 \\
\hline $66-70$ & 11 & 17 & 7 & 9 & 6 & 18 \\
\hline $71-75$ & 7 & 9 & 4 & 9 & 2 & 9 \\
\hline $76-80$ & 5 & 4 & 5 & 8 & 1 & 4 \\
\hline$>80$ & 3 & 10 & 3 & 7 & 2 & 9 \\
\hline Average & 5.66 & 8.5 & 4 & 6.5 & 2.16 & 8.33 \\
\hline
\end{tabular}

H2 blockers and NSAIDs were found to be used as selfmedication in $48.33 \%$ of individuals whereas supplements like multivitamins (B. complex and Calcium) were used in $46.66 \%$ of individuals. Others and respiratory drugs were used in $13.33 \%$ and $5 \%$ respectively.

Self-medication was found highest in >80years of age group, 2.33 average drugs/individuals. In 76-80, 66-70 and 60-65 age groups self-medication was $1.71,1.52$ and 1.91 average drugs/ individual respectively (Table 8).

Table 8: Age wise distribution of self medication.

\begin{tabular}{|lll|}
\hline Age (years) & Percentage $(\mathbf{N})$ & Average no of drugs \\
\hline $60-65$ & 12 & 1.91 \\
\hline $66-70$ & 18 & 1.52 \\
\hline $71-75$ & 11 & 1 \\
\hline $76-80$ & 7 & 1.71 \\
\hline$>80$ & 9 & 2.33 \\
\hline
\end{tabular}

Self-medication was 2.15 average drugs in males and in females it was 1.48 (Table 9).

Table 9: Sex wise distribution of self medication.

\begin{tabular}{|ll|}
\hline Sex & Average number of self medications \\
\hline Male & 2.15 \\
\hline Female & 1.48 \\
\hline
\end{tabular}

\section{DISCUSSION}

Geriatric population have increasing vulnerability to acquire multiple and chronic diseases with various complaints with atypical presentations, so the number of prescribed drugs are more.

In studies related to Polypharmacy like Robert L Maher et al, Dima M. Qata et al, and O'Dwyer M et al, females and old age have been predictors of polypharmacy. ${ }^{1,8,9}$ In our study, polypharmacy was found highest in the age group of 71-75 years (5.3 average number of drug consumption/day) Next highest with 60-65 years of age group (5.1). Comparing polypharmacy with respect to sex, it was found to be more in male individuals. (5.04) average drugs consumption per day compared to female (3.94). ${ }^{6}$ These findings are in comparison with the study Mohammed S et al.

In our study, out of 60 geriatric population, Polypharmacy, use of more than 5 drugs per day $58.3 \%$ of individuals.

Most common group of drugs used is Gastro intestinal system drugs (78.3\%) and most common drug being used is Tab. Ranitidine $140 \mathrm{mg}(51.66 \%)$ for peptic ulcer disease and acute gastritis. Highest use of GIT drugs was found in age group of 66-70years. This is similar to study by Shah et al, where Ranitidine, Aspirin and Diclofenac are reported as commonly utilized drugs. ${ }^{10}$ Similar results were found in the study by Rambhade $S$ et al, where Ranitidine, Multivitamins, Amlodipine, Ipratropium and Dinitrosalicylic acid are commonly observed drugs. ${ }^{11}$

Next commonly used group of drugs is NSAIDs $(68.33 \%)$ and most common drug among NSAIDs used is Tab. Diclofenac 50mg (46.7\%) for complaints of Knee Arthritis.

\section{Among cardiovascular drugs}

Antihypertensive drugs were prescribed in $53.3 \%$ of geriatrics, most commonly prescribed drug is Tab. Amlodipine 5mg (in 43.33\%).

Oral hypoglycaemic agents were prescribed in $30 \%$ of the individuals and most common prescribed drug is Tab. Metformin 500mg (28.33\%).

Self medication was found in $98 \%$ (in 58 individuals). It was most commonly associated with complaints of knee arthritis, peptic ulcer disease and as energy boosters (multivitamins). ${ }^{12}$ Highest number of self medication use was found in $>80$ age group (average is 2.33). Most common group of drug used as self medication are GIT drugs like $\mathrm{H}_{2}$ blockers/PPIs (Ranitidine, omeprazole) and NSAIDs like Diclofenac and Paracetamol (48.33\%). Next being supplement drugs like Cap. BC/T. Calcium. ${ }^{13}$

In a study conducted by Dima M. Qata et al, $42 \%$ was use of over the counter drugs. In our study, OTC drug usage is present $100 \%$ with atleast one drug use. ${ }^{8}$

Number of people clinically diagnosed with peptic ulcer disease/gastritis was $6 \%$ but the drugs taken by individuals was $31 \%$ which has lead to self medication.

Polypharmacy may sometimes lead to "prescribing cascades." Prescribing cascade is said when signs and 
symptoms (multiple and nonspecific) of an ADR is misinterpreted as a disease and a new treatment/drug therapy is further added to the earlier prescribed treatment to treat the condition. This inherits the potential to develop furthermore side-effects and thus making a prescribing cascade.

\section{The example of prescribing cascade}

Ranitidine prescribed to prevent side effect/prophylactic therapy in low dose Aspirin in patient without peptic ulcer history. ${ }^{5}$

Identifying and avoiding the polypharmacy can lead to better outcomes in the elderly patients and also helps in improving the quality of life. Medication review is an essential part in the elderly patient to avoid adverse effects that can be caused due to polypharmacy. ${ }^{1}$

In a study conducted by Andrew $\mathrm{J}$ Muir et al, simple intervention using MEDICATION GRID among physicians had significant impact on medication regimen complexity. Reduced polypharmacy by 0.92 per patient. ${ }^{14}$

The present study has analysed the incidence of polypharmacy with respect to age and sex and also about self medication which found to be major factor leading to polypharmacy.

Polypharmacy in elderly have found to be associated with negative health outcomes, but more of interventional studies are further needed to delineate the consequences associated with polypharmacy. Health care professionals should be aware of the risks and evaluate all medications at each patient visit to prevent polypharmacy and related problems in improving quality among geriatrics.

\section{CONCLUSION}

Polypharmacy was found in $58.3 \%$ of individuals and highest in age group between 71-75 years and self medication was found to be the most important factor leading to polypharmacy. To counteract the problems associated with Polypharmacy, interventional studies are needed to improve the quality of life of geriatrics patients.

\section{ACKNOWLEDGMENTS}

Authors would like to thank all staff in Department of Pharmacology, Hassan Institute of Medical Sciences and all participants of the study and staff of old age home "Kamadhenu Vruddhashrama" Hassan district, Karnataka.

Funding: No funding sources Conflict of interest: None declared
Ethical approval: The study was approved by the Institutional Ethics Committee of Hassan Institute of Medical Sciences (HIMS), Hassan

\section{REFERENCES}

1. Maher RL, Hanlon J, Hajjar ER. Clinical consequences of polypharmacy in elderly. Expert opinion on drug safety. 2014 Jan 1;13(1):57-65.

2. Ingle GK, Nath A. Geriatric health in India: Concerns and solutions. Indian Journal of community medicine. 2008 Oct 1;33(4):214.

3. Dutta M, Prashad L. Prevalence and risk factors of polypharmacy among elderly in India: Evidence from SAGE Data.

4. Salwe KJ, Kalyansundaram D, Bahurupi Y. A study on polypharmacy and potential drug-drug interactions among elderly patients admitted in department of medicine of a tertiary care hospital in Puducherry. Journal of clinical and diagnostic research: JCDR. 2016 Feb;10(2):FC06.

5. Dagli RJ, Sharma A. Polypharmacy: a global risk factor for elderly people. Journal of international oral health: JIOH. 2014 Nov; 6(6): i.

6. SS M, MK S, Vishnu VG, Jose F, Siraj ST, Anand VP. The Prevalence of Polypharmacy in South Indian Patients: A Pharmacoepidemiological Approach. Indian Journal of Pharmacy Practice. 2012 Jul; 5 (3):40.

7. Rahmawati F, Pramantara IP, Rohmah W, Sulaiman SA. Polypharmacy and unnecessary drug therapy on geriatric hospitalized patients in yogyakarta hospitals, Indonesia. Int J Pharm Pharm Sci. 2009 Nov;1(1):6-11.

8. Qata M. Dima. Use of Prescription ad OTC medications and dietary supplements among older adults, June 2009;300(50):2867-78.

9. O'Dwyer M, Peklar J, McCallion P, McCarron M, Henman MC. Factors associated with polypharmacy and excessive polypharmacy.

10. Shah BM, Hajjar ER. Polypharmacy, adverse drug reactions, and geriatric syndromes. Clinics in geriatric medicine. 2012 May 31;28(2):173-86.

11. Rambhade S, Chakarborty A, Shrivastava A, Patil UK, Rambhade A. A survey on polypharmacy and use of inappropriate medications. Toxicology international. 2012 Jan;19(1):68.

12. JH Gunitz. Incidence and Preventability of ADR events among older persons. March 2003;289(9):1107-16.

13. Muir AJ, Sanders LL, Wilkinson WE, Schmader K. Reducing medication regimen complexity: a controlled trial. Journal of general internal medicine. $2001 \mathrm{Feb}$ $1 ; 16(2): 77-82$.

14. Emily R, Hajjar A, Caferio C. Polypharmacy in elderly patients, The American J of Ger Poly. 2007;5(4):345-51.

Cite this article as: Rathod G, Nalini GK, Nagaral JV, Sahana GN, Deepak P, Prema M, et al. Factors associated with polypharmacy in geriatrics. Int $\mathrm{J}$

Basic Clin Pharmacol 2017;6:1763-7. 